\title{
Tsafon
}

Revue d'études juives du Nord

Rota Olivier, Les catholiques anglais et la " question juive » (1917-1967). D'une approche politique à une approche spirituelle

\section{Danielle Delmaire}

\section{(2) OpenEdition \\ Journals}

Édition électronique

URL : https://journals.openedition.org/tsafon/4508

DOI : $10.4000 /$ tsafon.4508

ISSN : 2609-6420

Éditeur

Association Jean-Marie Delmaire

Édition imprimée

Date de publication : 1 décembre 2021

Pagination : 150-152

ISSN : $1149-6630$

\section{Référence électronique}

Danielle Delmaire, «Rota Olivier, Les catholiques anglais et la « question juive » (1977-1967). D'une approche politique à une approche spirituelle », Tsafon [En ligne], 82 | 2021, mis en ligne le 01 décembre 2021, consulté le 12 février 2022. URL : http://journals.openedition.org/tsafon/4508 ; DOI : https:// doi.org/10.4000/tsafon.4508

Ce document a été généré automatiquement le 12 février 2022.

Tsafon. Revues d'études juives du Nord 


\title{
Rota Olivier, Les catholiques anglais et la "question juive " (1917-1967). D'une approche politique à une approche spirituelle
}

\author{
Danielle Delmaire
}

\section{RÉFÉRENCE}

Rota Olivier, Les catholiques anglais et la "question juive» (1917-1967). D'une approche politique à une approche spirituelle, Paris, éd. du Cerf, juin 2021, 656 p. $39 €$.

1 Auteur ou directeur de plusieurs ouvrages sur les relations inter-religieuses, Olivier Rota a soutenu en novembre 2019, à l'université de Reims, une habilitation à diriger des recherches. L'ouvrage qui vient de paraître, deux ans après, est la publication de son épais mémoire de soutenance. Il est actuellement maittre de conférences à l'université catholique de Lille.

2 Une recherche initiale, et bien antérieure, sur l'antisémitisme des catholiques en Grande-Bretagne, qui se double souvent d'une réflexion philosophique bien que l'auteur se défend d'être un historien des idées, s'est développée en une recherche sur les relations inter-religieuses pour aboutir à une étude substantielle sur les catholiques anglais et la "question juive ». La focalisation sur les catholiques mérite d'être retenue dans la mesure où ceux-ci constituent, en Angleterre, une minorité tout comme les Juifs qui les indisposent. Et ceci à la différence de la France, ou d'autres pays européens, où les catholiques sont majoritaires et dont la civilisation intègre les valeurs catholiques. Pour ses nombreux travaux constitutifs de son mémoire d'habilitation à diriger des recherches, Olivier Rota n'a pas ménagé sa peine, se rendant en Israël pour consulter des archives (Notre-Dame de Sion, Assomptionnistes, patriarcat latin etc.) ou à Rome, et principalement en Angleterre où il fréquenta les sœurs de Sion et d'autres milieux 
catholiques impliqués dans le dialogue entre Juifs et catholiques. Ce qui explique l'abondance des sources archivistiques, littéraires et de la presse. Près d'une trentaine de centres d'archives ont été visités et pas moins d'une cinquantaine de journaux ou revues ont été utilisés !

Une bibliographie non moins abondante laisse une large part aux publications en anglais et l'auteur ajoute une bibliographie pour chacun des huit chapitres qu'il rassemble en un appareil critique. La présence d'un index des noms de personnes est bien appréciable. Non négligeables également sont les annexes livrant des documents pour la plupart en anglais.

4 En outre, il faut souligner une écriture agréable à lire, le style est alerte et le vocabulaire est riche. Les arguments sont toujours exposés avec des références archivistiques ou bibliographiques grâce à de nombreuses notes qui informent aussi sur l'historiographie.

Dans son introduction, Olivier Rota invite à définir les termes tant il est vrai que le sens de certains d'entre eux varie selon le contexte politique et social. À commencer par " catholiques anglais » et la " question juive », la judenfrage des Allemands qui évolue en "question de l'État d'Israël», qui sont autant d'expressions méritant d'être bien précisées. Et plus encore les termes de "mission ", "apostolat " sont à comprendre différemment selon les années. Mais tout cela Olivier Rota l'explique fort bien : le but de la mission passe de la conversion au dialogue, à l'échange. Cette évolution n'est d'ailleurs pas le fait des seuls catholiques de Grande-Bretagne.

6 Le choix des bornes chronologiques est judicieux. L'année 1917 est, en effet, riche en événements décisifs pour l'Europe en guerre mais aussi pour, et surtout pour, la Grande-Bretagne. En 1917, rappelle Olivier Rota, la victoire des Bolcheviks bouleverse le champ religieux et va repositionner les catholiques, de Grande-Bretagne et d'ailleurs, vis à vis des Juifs que l'on assimile bien vite à l'athéisme communiste antichrétien. 1917 c'est encore, pour la Grande-Bretagne, la pénétration militaire en Palestine, avec l'entrée des troupes d'Allenby dans Jérusalem, et la lettre que Balfour envoie à Lionel de Rothschild l'assurant $d u$ soutien $d u$ Gouvernement de Sa Majesté pour l'établissement d'un foyer national juif en Palestine. Les bases d'un développement sioniste sont alors jetées, ce qui va inviter les catholiques à revoir leur relation avec les Juifs qui désormais sont supposés prendre possession des lieux saints. Bref, le choix de l'année1917 est tout à fait pertinent pour borner cette étude. Et celui de 1967 l'est tout autant : le concile du Vatican II vient de se terminer avec la déclaration Nostra Ætate qui proscrit l'antijudaïsme. C'est aussi l'année de la guerre des Six-Jours qui change la vision que l'on peut avoir d'Israël et, en conséquence, des Juifs.

On peut relever quelques idées fortes.

- En premier lieu vient le parallèle tout à fait recevable entre catholiques irlandais et Juifs, en tant que minorités religieuses discriminées en Angleterre et plus précisément dans l'East End londonien où ces communautés connaissent un peuplement dense. Et la présence d'un Zangwill n'a pas été oubliée tant pour sa lutte contre l'antisémitisme que pour son soutien à la cause sioniste. Cette particularité anglaise du catholicisme méritait en soi une étude approfondie. Encore que, dans un autre contexte de libération nationale, les Italiens s'habillaient, eux aussi, des habits des Hébreux gagnant la Terre Promise (Verdi) tout comme les Irlandais dans leur imaginaire se voyaient dans la peau de Juifs.

- Les pages sur l'antisémitisme des penseurs catholiques anglais, tels Belloc et les frères Chesterton, sont particulièrement fortes. On pourrait y voir l'influence des catholiques 
français, notamment pour Belloc. Car, comme le précise Olivier Rota, l'antisémite catholique anglais développe les mêmes arguments que le catholique français pétri d'antisémitisme.

- La « question juive » finit par devenir « la question du sionisme » et ceci dès les années 1930 puisque la Grande-Bretagne a hérité d'un mandat sur la Palestine. Dans la pensée catholique, en Angleterre et ailleurs, le sionisme se teinte d'antichristianisme. L'évolution sémantique des termes finit par engendrer une évolution politique et religieuse du positionnement des catholiques. Or parallèlement, la persécution des nazis préoccupe les catholiques, ainsi apparaissent et se développent des mouvements favorables aux Juifs comme le CCJ (Council of Christians and Jews) pour ne citer que lui. Cette contradiction a bien été analysée par Olivier Rota.

- Autre idée forte d'importance : le rôle efficace des Juifs convertis au catholicisme dans la nouvelle approche de la mission envers les Juifs, qui se transforme en dialogue. Pour ne citer que les plus connus : Mgr Osterreicher, mais encore Mgr Baum, et aussi quelques sœurs de Sion, ou encore des laïcs comme Mme Marinoff. Tout comme la présence des dominicains dans ce changement. On est loin des Liberman et des Ratisbonne du XIX ${ }^{\mathrm{e}}$ siècle qui n'avaient que la conversion à offrir à leurs anciens coreligionnaires. Rappelons au passage qu'en France et en Palestine-Israël, on retrouve aussi des Juifs convertis au catholicisme et des dominicains aux premiers rangs des partenaires catholiques du dialogue inter-religieux.

- La définition de l'œcuménisme occupe aussi plusieurs paragraphes, à juste titre tant il est vrai que sa limitation stricte aux relations intra-chrétiennes fut, et est encore, discutée, parfois âprement.

- Les progrès du dialogue judéo-catholique ont leur place dans l'étude de l'après-guerre. Les pages sur l'influence de Jules Isaac, le fondateur de l'Amitié judéo-chrétienne en France en 1948, me paraissent complètement neuves, de même celles sur la présence anglaise à la conférence de Seelisberg puis de Fribourg. Elle-même avait été précédée par la conférence d'Oxford qui prépare les réflexions à mener. En France, les catholiques manifestent, au tout début, une certaine méfiance face à ce mouvement inter-religieux, il semble qu'en Angleterre, avec la conférence d'oxford, les craintes ne soient pas de mise.

- En ce qui concerne les pages sur le concile du Vatican II, on peut regretter la mise à l'ombre de la présence des sœurs de Notre-Dame de Sion dans les coulisses. Elles ont beaucoup agi en sous-main mais peut-être n'y avait-il pas beaucoup de religieuses anglaises parmi elles. En revanche il faut reconnaître le bien-fondé du rappel du contexte des années 1960 avec l'affaire de la pièce de théâtre Le Vicaire, qui d'ailleurs secoua aussi la France, et avec le procès Eichman qui bouleversa la population israélienne et juive dans le monde mais aussi les non-Juifs et au premier chef les catholiques. Ces événements ont pu avoir un écho dans les couloirs du Vatican.

8 Après la lecture, il reste à se réjouir d'une telle publication très bien documentée et qui renouvelle très certainement l'histoire de certaines étapes du dialogue entre catholiques et juifs qui évolue de l'animosité à l'amitié. 